\title{
Habitat islands outside nature reserves - Threatened biodiversity hotspots of grassland specialist plant and arthropod species
}

\author{
Balázs Deák ${ }^{\mathrm{a}}$, Orsolya Valkób ${ }^{\mathrm{b}}$, Dávid D. Nagy ${ }^{\mathrm{a}}$, Péter Török ${ }^{\mathrm{c}}$, Attila Torma ${ }^{\mathrm{d}}$, Gábor Lơrinczi ${ }^{\mathrm{d}}$, \\ András Kelemen ${ }^{\mathrm{b}, \mathrm{e}}$, Antal Nagy ${ }^{\mathrm{f}}$, Ádám Bede ${ }^{\mathrm{g}}$, Szabolcs Mizser ${ }^{\mathrm{a}}$, András István Csathóh ${ }^{\mathrm{h}}$, \\ Béla Tóthmérész ${ }^{\mathrm{a}, \mathrm{i}}$
}

${ }^{a}$ MTA-DE Biodiversity and Ecosystem Services Research Group, Debrecen, Hungary

${ }^{\mathrm{b}}$ MTA-DE Lendület Seed Ecology Research Group, Debrecen, Hungary

${ }^{\mathrm{c}}$ MTA-DE Lendület Functional and Restoration Ecology Research Group, Debrecen, Hungary

${ }^{\mathrm{d}}$ University of Szeged, Department of Ecology, Szeged, Hungary

${ }^{\mathrm{e}}$ MTA's Post Doctoral Research Program, Hungary

${ }^{\mathrm{f}}$ University of Debrecen, Faculty of Agricultural and Food Sciences and Environmental Management, Debrecen, Hungary

${ }^{\mathrm{g}}$ University of Szeged, Department of Geology and Paleontology, Hungary

${ }^{\text {h }}$ Körös-Maros National Park Directorate, Szarvas, Hungary

${ }^{\mathrm{i}}$ University of Debrecen, Faculty of Science and Technology, Department of Ecology, Debrecen, Hungary

\section{A R T I C L E I N F O}

\section{Keywords:}

Kurgan

Land use

Protected area

Refuge

Sacred site

Steppe

\begin{abstract}
A B S T R A C T
In transformed landscapes, many populations of grassland specialist plant and animal species live outside the few protected areas and are often preserved on 'small natural features' (SNFs) such as road verges, field margins and rocky outcrops. In the steppe and forest steppe zones of Eurasia ancient burial mounds (kurgans) are widespread SNFs providing refuge for grassland species. Based on a large-scale botanical and zoological survey of 138 kurgans in Hungary, we compared the management regimes, the presence of threatening factors and the conservation potential of kurgans embedded in non-protected transformed landscapes and in protected areas. We found that kurgans extend the borders of the protected areas by maintaining populations of grassland specialist plants and arthropods (ants, orthopterans, true bugs and rove beetles) even in transformed landscapes. We revealed that the lack of proper management, the presence of anthropogenic disturbances and encroachment of woody species are the most considerable threats to the long-term maintenance of biodiversity on kurgans located outside the protected areas. For their effective conservation a new approach is needed, which can cope with the small area and dispersed localities of the kurgans and can integrate them into the network of other SNFs on a landscape-level. As the ecological importance of kurgans is disproportionate to their size conservation actions focusing on their protection offers a greater rate of return of the efforts than can be expected in case of larger continuous sites.
\end{abstract}

\section{Introduction}

Land use intensification over the past centuries has become one of the major threats to biodiversity at multiple scales (Lindborg et al., 2014). Many formerly extensive natural habitats have been transformed into agricultural fields or urban areas (Biró et al., 2018; Deák et al., 2016a; Tscharntke et al., 2012). Because of these drastic losses, remnants of natural habitats have been fragmented and isolated (Fletcher et al., 2018). Together with the cessation of traditional management regimes, changes in landscape composition and configuration pose serious threats to biodiversity worldwide (Brückmann et al., 2010;
Fletcher et al., 2018). Large stands of natural habitats are generally preserved in the few protected areas; however, the biodiversity conservation potential of these areas is limited (Colding and Folke, 2001). Many protected areas are designated in places which otherwise cannot be utilised by intensified land use techniques. Thus, their number and size are disproportionally smaller in fertile lowlands, and in many cases they are not able to cover all endangered habitat types and species (Bhagwat and Rutte, 2006). Therefore, in transformed lowland landscapes, a considerable proportion of the biodiversity is present in small fragments located outside protected areas (Colding and Folke, 2001; Poschlod and Braun-Reichert, 2017). Nowadays it is increasingly

\footnotetext{
* Corresponding author at: MTA-DE Lendület Seed Ecology Research Group, Egyetem tér 1, Debrecen, H-4032, Hungary.

E-mail address: valkoorsi@gmail.com (O. Valkó).
} 
recognized that besides the protected areas biodiversity conservation should also focus on the network of habitat fragments dispersed throughout the whole landscape (Lindborg et al., 2014; Frascaroli et al., 2016).

In transformed landscapes, there are many 'small natural features' (SNFs) such as field margins, forest fringes, hedges, mid-field islets, old trees, steep slopes of riverbanks, rocky outcrops, road and railway verges that can act as refuges for grassland species (Jakobsson et al., 2018; Lindborg et al., 2014). These features often persist because they are less suitable for cultivation (Poschlod and Braun-Reichert, 2017). Despite their small size SNFs have considerable conservation importance, since they increase the area of available habitats for grassland species and thus the landscape-level species diversity (Lindborg et al., 2014). By the spillover of species typical to semi-natural habitats from SNFs they can also positively affect ecological functioning and ecosystem services (such as biological pest control or pollination) on a much larger area than otherwise would be expected from their size (Hunter et al., 2017). Given the various responses of different taxa to the effects of management, habitat conditions and landscape context, a multi-taxon approach is needed to understand the mechanisms influencing their assemblages on SNFs.

In some special cases, long-term existence of SNFs is also supported by their sacred, historical and cultural values (Bhagwat and Rutte, 2006). Sacred natural sites such as old cemeteries, churchyards, shrines and sacred grooves have centuries or millennia long histories, and due to the religious respect and social taboos they primarily have been recognised and used for their spiritual values, and not for agricultural production (Dudley et al., 2009; Kowarik et al., 2016; Löki et al., 2019; Molnár V. et al., 2017; Rutte, 2011). Consequently, sacred sites have often been utilised and managed in an extensive way for centuries (Dudley et al., 2009). Even though sacred natural sites are not primarily conservation areas, they have a considerable conservation role even in transformed landscapes. In many regions together with other SNFs, they form a large network of semi-natural habitats beyond the official protected areas, and they exist because of the willingness of the local people to protect them (Bhagwat and Rutte, 2006; Rutte, 2011).

Ancient burial mounds, the so-called 'kurgans' of the steppe and forest steppe biomes are one of the most widespread and abundant sacred natural sites in Eurasia. There are approximately 400,000-600,000 kurgans from Hungary to Mongolia (Deák et al., 2016a). Kurgans were built by nomadic Indo-European tribes (such as the Yamnayas, Scythians and Sarmathians) and ancient Turkish cultures (e.g. Kipchak, Khazar, Cumanian groups) for burial purposes predominantly during the Copper, Bronze and Iron Ages, the Migration Period and Middle Ages (Sudnik-Wójcikowska and Moysiyenko, 2014; Tóth et al., 2018). The mound which generally ranges between $0.5-15 \mathrm{~m}$ in its height and 5-55 $\mathrm{m}$ in its radius was built upon a central pit grave, and generally was built from the topsoil of the neighbouring areas (Dembicz et al., 2018; Lisetskii et al., 2016). Kurgans have been considered as sacred places for millennia, and they are important elements of the cultural and historical heritage of many Eurasian countries (Deák et al., 2016a). Kurgans also have a high conservation importance, especially in the transformed landscapes of Central- and Eastern-Europe and the European part of Russia (Deák et al., 2016a, Deák et al., 2016b; Sudnik-Wójcikowska and Moysiyenko, 2014). These SNFs often act as the last remnants of grassland habitats embedded in arable fields, and despite the century-long isolation, they often harbour viable populations of grassland species (Dembicz et al., 2018). The biodiversity potential of the kurgans is considerably supported by their long-term existence and their special hill-shaped form (Deák et al., 2016b; Dembicz et al., 2018). Grasslands on kurgans have been in existence for an extended period, thus they have the potential to maintain temporal habitat connectivity and preserve formerly existing species pools despite the profound changes in the surrounding landscapes (Deák et al., 2016b; Hunter et al., 2017; Poschlod and Braun-Reichert, 2017).

Given their small area and dispersed distribution, the protection and management of kurgans are generally poorly realised. Active protection is generally achieved when they are embedded in large protected areas, where they passively benefit from the conservation regulations. Like other SNFs, out of the protected areas kurgans are especially endangered by ad hoc destruction by land managers, as the costs of destruction and the probability of the authorities detecting the destruction is low (Bauer et al., 2017). Furthermore, the altered land use regimes (such as abandonment and the intensification of land use), anthropogenic and natural disturbances might also pose serious challenges for their conservation (Deák et al., 2016a; Tóth et al., 2018). In Hungary, the application of agri-environmental schemes seemed to be an important but only partial solution for this problem. According to the regulations of the Common Agricultural Policy (CAP; Council Regulation EC 73/2009) farmers cannot plough and afforest kurgans. The restrictions successfully suppressed these two harmful land-use practices on the kurgans, but do not regulate other processes (management, spontaneous woody encroachment and restoration) that can also influence the populations of grassland species (Tóth et al., 2018).

\section{Aims}

Based on the data from our large-scale botanical and zoological survey of 138 kurgans in Hungary, we evaluated the similarities and differences in the management, the presence of threat factors and the conservation potential of kurgans embedded in non-protected heavily transformed agricultural landscapes and in extensive protected areas represented by Natura 2000 areas. We aimed to reveal the conservation potential of kurgans located outside the protected areas, evaluate their conservation state compared to the ones located inside the protected areas, and to provide an ecological context for developing more targeted conservation strategies. The application of a multi-taxon focus allowed us to detect the specific responses of taxa with different dispersal abilities on the factors acting outside and inside the protected areas. We proposed the following questions: (i) Are there any differences in the characteristics (e.g. area, height and slope inclination) of the kurgans located inside and outside the protected areas? (ii) Is there a difference in the management regimes (grazing, mowing, unmanaged) and in the presence of anthropogenic disturbance factors (roads, buildings, garbage) acting on kurgans outside and inside the protected areas? (iii) Can kurgans contribute to the maintenance of grassland specialist plants and arthropods outside the protected areas? (iv) What are the factors affecting the species richness and abundance of grassland specialist species on the kurgans located inside and outside the protected areas? (v) Does the species composition of grassland specialist plants and arthropods differ on kurgans outside and inside protected areas?

\section{Material and methods}

\subsection{Study sites}

The study area is in the Great Hungarian Plain and covers approximately $50,000 \mathrm{~km}^{2}$. The area has a continental climate with an annual precipitation of $538 \mathrm{~mm}$ and mean annual temperature of $10.4 C^{\circ}$ (Fick and Hijmans, 2017). The historical landscape was characterised by meadow steppes, forest steppes, edaphic steppes and wetlands, but mainly due to agricultural intensification since the 18th century there have been considerable losses in the area of the grasslands (Biró et al., 2018). These characteristics of the study area make it a good representative for the historical landscape changes typical to European open landscapes. Small fragments of grasslands generally remained in field margins, road verges, old cemeteries and kurgans. These grassland fragments are often surrounded by intensive agricultural fields and urban areas, severely affected by human activities. Extensive grassland stands are mostly located inside the protected areas, which are well represented by the Natura 2000 network, which 


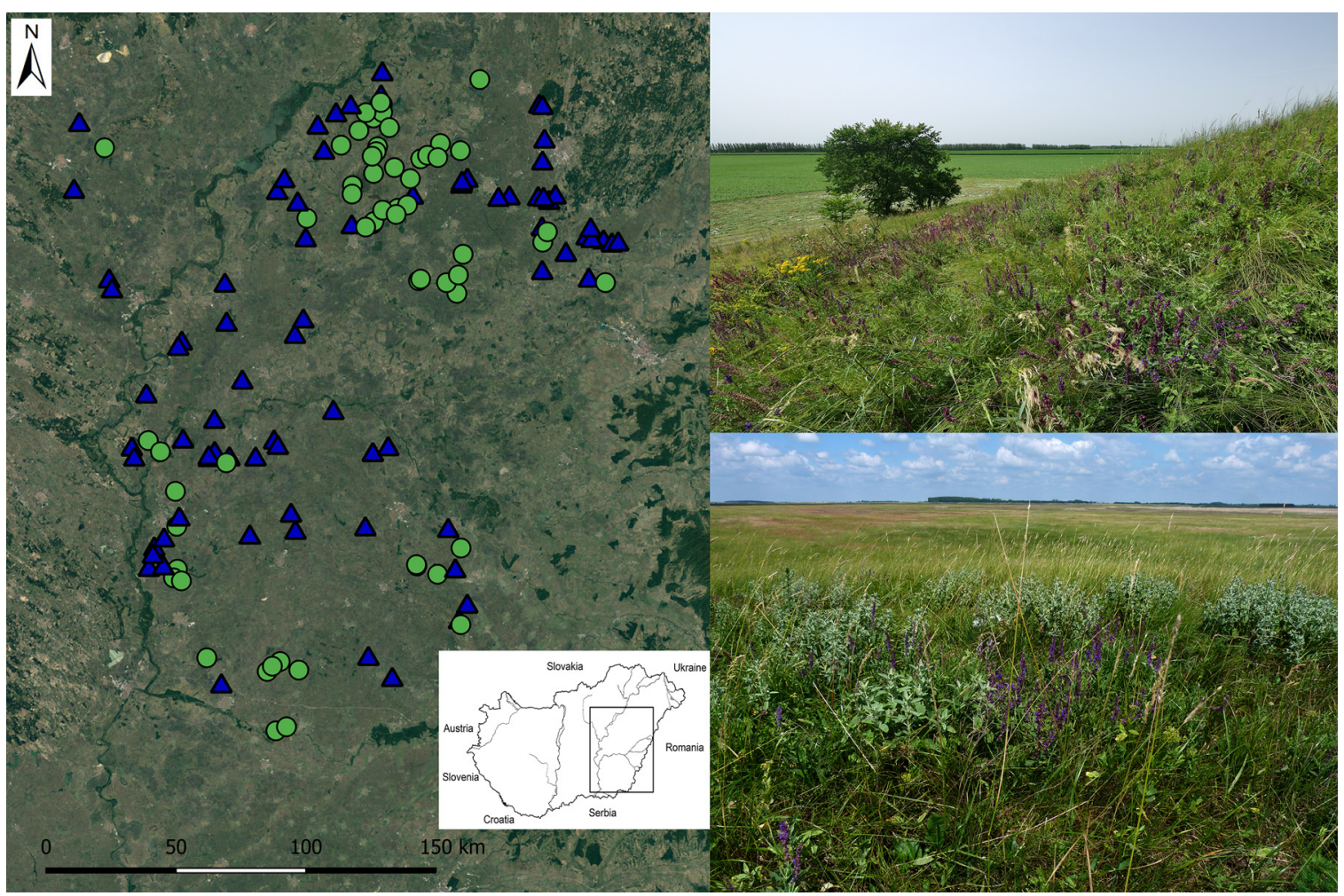

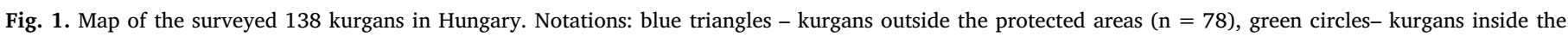

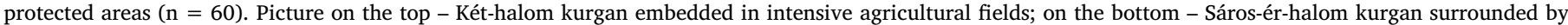
grasslands. (For interpretation of the references to colour in this figure legend, the reader is referred to the web version of this article).

was designated to provide a protected network for endangered species and habitats listed in the Annexes of the Habitats Directive (Council Directive, 1992). Natura 2000 sites are managed in an extensive, sustainable way. In case of grasslands it means that the applied management can be moderate grazing or mowing. No fertilisation, drainage or irrigation is allowed, the landowner should make efforts to suppress invasive species, and in case of arable lands the application of chemicals is limited. In our survey the protected areas were represented by a total of 21 Natura 2000 sites which were characterised by semi-natural grasslands (55.6\%), extensive arable lands and infrastructure (33.1\%), wetlands $(6.1 \%)$ and woody vegetation $(5.2 \%)$ (EEA, 2019). The mean area of the sites was 22,342 ha.

\subsection{Field survey}

Altogether, we surveyed 138 kurgans harbouring loess grasslands (Fig. 1). Loess grasslands of the Pannonian region are considered as the grassland component of the forest steppes (Biró et al., 2018). Their uniqueness is acknowledged by the Habitats Directive of the European Union; 'Pannonic loess steppic grasslands' are listed as priority habitats. 60 of the surveyed kurgans were located inside the protected areas (Natura 2000 areas), 78 were embedded in transformed agricultural landscapes outside the protected areas.

We surveyed the kurgans from May to June in three consecutive years (2014-2016); each kurgan was surveyed once. During the field survey, we recorded the physical attributes (height, slope inclination, area) of the kurgans, the current management (grazing, mowing, unmanaged), and the presence of disturbance factors threatening grassland biodiversity (roads, permanent modern non-sacred buildings, garbage deposition). A disturbance factor was considered as relevant if it affected at least $10 \%$ of the kurgan's surface. We recorded the species list and the percentage cover of vascular plants on each kurgan, considering one kurgan as one sample unit. To avoid over- or under-sampling of the vegetation we standardised the sampling time with the area of the kurgan, three surveyors spent $10 \mathrm{~min}$ per 0.1 ha for recording species lists. Sweep-net and D-vac sampling methods were used to collect arthropods, namely ants (Hymenoptera: Formicidae), orthopterans (Orthoptera), true bugs (Heteroptera) and rove beetles (Coleoptera: Staphylinidae) along four transects positioned according to the four cardinal directions from the bottom to the top of kurgans. Sweep-net samples were taken with 50 sweeps in each transect. All arthropods collected by a 40-cm-diameter sweep-net were transferred to a labelled plastic bag. D-vac with 12-cm-diameter sampling cone and collecting bag was placed 15 times (held above the soil surface for $5 \mathrm{~s} /$ placement) along each transect. After 15 placements, the collecting bag was removed from the D-vac, the collected arthropods were also stored in a labelled plastic bag. Arthropods of the selected taxa were extracted from the samples and preserved in $70 \%$ ethanol. Each specimen was identified to species level using standard keys.

\subsection{Data analyses}

We calculated the height of the kurgans using the contour lines of the 1:10,000 topographic map of Hungary (Unified National Cartography System). Inclination was expressed as the mean inclination of the northern, southern, eastern and western slopes. We calculated the surface area of the kurgans using the formula of an elliptic-based cone for which we measured the shorter and longer radius and the height of the objects.

We considered species of dry grasslands, i.e. herbaceous species of the phytosociological classes Festuco-Brometea and FestucoPuccinellietea as grassland specialist plants (Borhidi, 1995). Arthropod species were considered grassland specialist based on (i) their specific habitat requirements typical to dry grassland habitats (i.e. warm and dry habitat conditions, preference for open habitats); (ii) their dietary preferences and/or (iii) their overwintering plant preferences. For a detailed list of grassland specialist taxa, see Appendix A-E.

To assess the overall conservation status of the kurgans, we used a 
naturalness score by calculating the cover-weighted mean score of social behaviour type (SBT) categories for plant species (Borhidi, 1995). The SBT classification is based on the model of Grime (1979) and was adapted for the Hungarian conditions. Naturalness score expresses the role of individual species in the plant communities and provides information about the community regarding its stability, regeneration ability, naturalness and degree of disturbance. Species were assigned into nine functional groups with different SBT index scores: specialists $(+6)$, competitors $(+5)$, generalists $(+4)$, natural pioneers $(+3)$, disturbance-tolerants $(+2)$, weeds $(+1)$, introduced species $(-1)$, ruderal competitors $(-2)$ and adventive competitors $(-3)$. These categories represent a gradient from the species typical of natural habitats to those typical of degraded habitats. As indicators of detrimental habitat changes, we also used the total percentage cover of woody species and the total cover and species richness of problem-species (species that are introduced, ruderal competitors or adventive competitors) for each kurgan.

We used Generalised Linear Models (GLMs) to reveal the differences in the kurgan characteristics (height, slope, area), percentage cover of woody and problem-species, naturalness scores and the species richness and abundance of grassland specialist taxa (plants, ants, orthopterans, true bugs and rove beetles) on kurgans outside and inside the protected areas. The species richness scores were fitted with GLMs using a Poisson distribution and log link function. All other scores were analysed using Gaussian distribution and log link function. For testing the differences between the management (grazing, mowing, unmanaged) on kurgans outside and inside the protected areas we used multinomial logistic regression, and for the presence of disturbance factors (roads, buildings, and garbage deposition) we used binary logistic regressions. For the calculations we used the program SPSS v.22 (IBM Corp, 2013).

For testing the factors that affect species richness and abundance of grassland specialist species we used GLMs and model selection. Model selection was used to evaluate multiple regression models and to select those which explained the relationship between species richness and abundance of grassland specialist taxa and the studied explanatory variables the best (Burnham and Anderson, 2002). Explanatory variables were the following: kurgan height, slope and area, percentage cover of woody species, presence of management (managed or abandoned) and level of disturbance (0-3 grade, calculated from the presence of roads, buildings and garbage); their effects were tested separately on the datasets of kurgans outside and inside the protected areas. We calculated the variance inflation factors (VIF) between all explanatory variables to test for multicollinearity ('faraway' package in R; Faraway, 2014). As the VIF was lower than 1.7 (i.e. the rate of multicollinearity was negligible) in each case, we considered all explanatory variables as uncorrelated and used them for the statistical analyses. To assess the effect of the explanatory variables on the grassland specialist taxa, we fitted GLMs for all possible combinations of the studied explanatory variables. We calculated the values of Akaike's Information Criterion corrected for a small sample size (AICc) for each model. We assessed the corresponding Akaike weight of each model representing the relative likelihood of a model later used to estimate model-averaged parameter values. Then we selected models with substantial support for calculating the significance and importance of explanatory variables with Z statistics using the 'MuMIn' package (Barton, 2011) in an R statistical environment (R Core Team, 2019).

To test for significant differences in the species composition of grassland specialist taxa we performed one-way PERMANOVA using the Bray-Curtis similarity index with 9999 randomisations. Calculations were performed by the PAST software (Hammer et al., 2001).

\section{Results}

The area of kurgans located outside and inside the protected areas was similar. Kurgans located outside the protected areas were higher and had slightly steeper slopes than the ones inside the protected areas
(Table 1). Based on the results of the multinomial logistic regression management of kurgans outside and inside the protected areas were different (Chi-Square $=13.983 ; \mathrm{p}=0.001$ ). We found that the number and relative proportion of grazed kurgans were lower outside $(n=5$; $6.4 \%)$ than inside the protected areas $(n=18 ; 30.0 \%)$. The number of unmanaged kurgans was higher outside the protected areas $(n=63$; $80.8 \%)$ than inside $(\mathrm{n}=37 ; 61.7 \%)$. The number of mown kurgans was similar outside $(n=10 ; 12.8 \%)$ and inside $(n=5 ; 8.3 \%)$ the protected areas. Based on the results of the binomial logistic regression the presence of roads (Wald $=1.867 ; \mathrm{p}=0.172$ ), buildings $($ Wald $=2.525$; $\mathrm{p}=0.112$ ) and the rate of garbage deposition (Wald $=3.150$; $\mathrm{p}=0.076$ ) was similar outside and inside the protected areas. The number of kurgans with roads was sixteen $(20.5 \%)$ outside and seven $(11.7 \%)$ inside the protected areas. Presence of buildings was typical on nine (11.5\%) kurgans outside, and thirteen (21.7\%) kurgans inside the protected areas. The number of kurgans with garbage deposition was eight $(10.3 \%)$ outside and one inside $(1.7 \%)$ the protected areas.

Species richness and percentage cover of problem-species, and the percentage cover of woody species were higher, while the naturalness scores calculated for the total vegetation and for the herbaceous species were lower on kurgans located outside the protected areas (Table 1). The studied kurgans harboured a high diversity and abundance of grassland specialist plant and arthropod species; their biodiversity was independent from the protection status. We did not detect significant differences in the species richness and abundance of grassland specialist plant and arthropod species on kurgans located outside and inside the protected areas. On the total area of 38.9 ha of the 138 studied kurgans, we found altogether 446 vascular plant species, 87 of which were grassland specialists (Borhidi, 1995) (Appendix A). The surveyed kurgans harboured 23 red-listed plant species such as Carduus hamulosus, Cynoglottis barrelieri and Sisymbrium polymorphum. The total species richness of arthropods was 357. We found 21 ant, 18 orthopteran, 76 true bug and 20 rove beetle grassland specialist species. The number of endangered or red-listed arthropod species was 61 (Appendix B-E).

The results of the model selection are summarised in Table 2 . We found that outside the protected areas the species richness and abundance of grassland specialist plants were higher on higher kurgans compared to lower ones. Inside the protected areas higher kurgans hold higher species richness of grassland specialist orthopterans. Outside the protected areas the abundance of grassland specialist ants and rove beetles were lower on kurgans with steep slopes. Inside the protected areas the species richness of grassland specialist plants was higher on kurgans with steep slopes. Outside the protected areas kurgans with a large area were characterised by a slightly smaller cover of grassland specialist plants than the small ones. Outside the protected areas the species richness of grassland specialist true bugs was lower on managed kurgans than on unmanaged ones. Managed kurgans held higher species richness and cover of grassland specialist plants inside the protected areas. Species richness of grassland specialist plants and true bugs was lower on kurgans characterised by a high level of disturbance both outside and inside the protected areas. Species richness of grassland specialist true bugs, and the abundance of grassland specialist plants, ants and true bugs were lower on kurgans with a high woody cover outside the protected areas. Inside the protected areas the species richness of grassland specialist plants was lower on kurgans with a high woody cover. Assemblages of grassland specialist plants, ants and orthopterans differed significantly on kurgans outside and inside the protected areas (PERMANOVA, Table 3). There was no difference between the assemblages of grassland specialist true bugs and rove beetles outside and inside protected areas.

\section{Discussion}

\subsection{Characteristics of the kurgans}

The area of the studied kurgans was small (mean 
Table 1

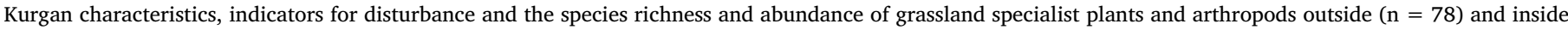

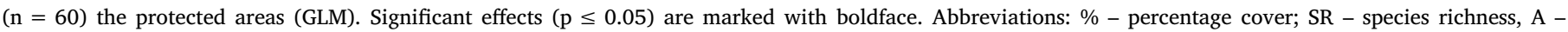
abundance.

\begin{tabular}{|c|c|c|c|c|}
\hline & Outside protected areas (mean \pm SE) & Inside protected areas (mean $\pm \mathrm{SE}$ ) & $\mathrm{F}$ & $p$ \\
\hline \multicolumn{5}{|l|}{ Kurgan characteristics } \\
\hline Area $\left(\mathrm{m}^{2}\right)$ & $2,213.94 \pm 165.22$ & $2,271.37 \pm 210.13$ & 0.048 & 0.826 \\
\hline Height (m) & $5.99 \pm 0.36$ & 4.390 .25 & 5.527 & 0.020 \\
\hline Slope inclination (degrees) & $14.65 \pm 0.65$ & $12.75 \pm 0.77$ & 3.586 & 0.060 \\
\hline \multicolumn{5}{|l|}{ Indicators for disturbance } \\
\hline Woody species (\%) & $24.98 \pm 2.99$ & $11.63 \pm 2.74$ & 6.994 & 0.009 \\
\hline Problem-species (SR) & $3.55 \pm 0.15$ & $2.93 \pm 0.15$ & 8.016 & 0.005 \\
\hline Problem-species (\%) & $17.27 \pm 2.19$ & $10.75 \pm 1.67$ & 4.312 & 0.040 \\
\hline Naturalness score (herbaceous vegetation) & $1.79 \pm 0.12$ & $2.22 \pm 0.16$ & 4.928 & 0.028 \\
\hline Naturalness score (total vegetation) & $1.18 \pm 0.15$ & $1.83 \pm 0.18$ & 7.253 & 0.008 \\
\hline \multicolumn{5}{|l|}{ Grassland specialists } \\
\hline Plants (SR) & $6.94 \pm 0.48$ & $8.07 \pm 0.63$ & 1.687 & 0.196 \\
\hline Plants (\%) & $26.75 \pm 2.25$ & $31.63 \pm 2.86$ & 1.671 & 0.198 \\
\hline Ants (SR) & $4.92 \pm 0.23$ & $4.67 \pm 0.31$ & 0.450 & 0.504 \\
\hline Ants (A) & $108.96 \pm 13.94$ & $123.60 \pm 15.20$ & 0.509 & 0.477 \\
\hline Orthopterans (SR) & $2.14 \pm 0.19$ & $2.12 \pm 0.24$ & 0.006 & 0.936 \\
\hline Orthopterans (A) & $29.73 \pm 5.15$ & $48.22 \pm 9.49$ & 3.113 & 0.080 \\
\hline True bugs (SR) & $3.97 \pm 0.37$ & $3.90 \pm 0.43$ & 0.017 & 0.895 \\
\hline True bugs (A) & $15.12 \pm 2.79$ & $10.93 \pm 2.05$ & 1.205 & 0.274 \\
\hline Rove beetles (SR) & $0.23 \pm 0.06$ & $0.30 \pm 0.07$ & 0.531 & 0.467 \\
\hline Rove beetles (A) & $0.42 \pm 0.21$ & $0.35 \pm 0.08$ & 0.082 & 0.776 \\
\hline
\end{tabular}

$2,238.91 \pm 130.17 \mathrm{~m}^{2}$; range $84-7,297 \mathrm{~m}^{2}$ ) especially compared to the size categories of grassland habitat islands reported in other studies $\left(1,000-8,800 \mathrm{~m}^{2}\right.$ in Rösch et al., 2015; $1,000-2,400 \mathrm{~m}^{2}$ in Brückmann et al., 2010). Interestingly, the area of the kurgans was the same outside and inside the protected areas. Our study showed that kurgans even with a small size can hold grassland habitats in transformed landscapes. The explanation for this phenomenon lays in the special shape of the kurgans. As shown by other studies, some SNFs proved to be less prone to land use intensification than others, as their physical parameters hamper their agricultural utilisation. For instance, the infertile and solid surface of the rocky outcrops or the extremely steep slopes of the riverbanks can preserve grassland vegetation in otherwise intensively used landscapes (Dembicz et al., 2016; Fitzsimons and Michael, 2017). Similarly, our results show that high kurgans with a considerable elevation could prevent ploughing and could preserve grasslands even outside the protected areas.

\subsection{Management}

Decline of biodiversity on SNFs is often associated with abandonment, as the management of small, dispersed sites which are often difficult to access implies extraordinarily high costs and organisation efforts (Deák et al., 2016b; Valkó et al., 2018a). In line with these findings we also found that the proportion of unmanaged kurgans was higher outside than inside the protected areas, where the management is supported by several means of management infrastructure and subsidies provided for land users. High proportion of unmanaged kurgans outside the protected areas is also attributed to landscape-level land use changes and to the isolation of grassland habitats. On the one hand, the shift from extensive to intensive agriculture leads to a decrease of extensively grazing livestock; therefore, in many regions habitats formerly managed by grazing became abandoned (Pakeman et al., 2016; Valkó et al., 2018b). On the other hand, due to the drastic loss and fragmentation of grasslands in many regions grazing by cattle or sheep is not feasible anymore, as this kind of management requires extensive, continuous grassland areas (Poschlod et al., 1998). Cessation of grazing is especially typical on SNFs, which are often embedded in ploughlands or urban areas, thus are inaccessible for grazing livestock (Deák et al., 2018; Poschlod et al., 1998). Our results confirmed this pattern; whilst grazing was typical on $30 \%$ of the kurgans situated inside the protected areas, proportion of grazed kurgans was only $6.4 \%$ outside the protected areas. The lack of biomass removal, trampling and nutrient input by grazers might have a negative effect on the species richness and habitat structure of unmanaged grasslands (Tälle et al., 2016). Furthermore, livestock as dispersal vectors have also an important role in the meta-population dynamics of grassland specialist species (Deák et al., 2018; Heinken and Weber, 2013).

As shown by our results, mowing might provide a feasible alternative for the management of isolated SNFs. Mowing can be applied even on small isolated habitat fragments, does not require expensive infrastructure, and can be an economic option even for small farms to produce forage for a limited number of livestock (Jakobsson et al., 2018). In the studied kurgans, the presence of mowing was partly connected to small-scale farming and was also often related to the sacred state of the kurgans (Deák, unpublished data). SNFs with a sacred importance generally do not face the problems associated with abandonment, even if they are situated outside the protected areas (Frascaroli et al., 2016; Rutte, 2011). Because of their sacred function, the local population often sustains the traditional extensive management of these sites. For example, in churchyards and cemeteries the extensive mowing, and in sacred grooves the prohibition of intensive forestry management can maintain the original species pool (Bhagwat and Rutte, 2006; Löki et al., 2019). Kurgans harbouring statues, cemeteries and sanctuaries are often mown by scythe or lawnmower machine to provide a well-kept appearance for the visitors, thereby ensuring the continuous management of grasslands.

\subsection{Disturbance factors}

Landscape-level protection is supposed to reduce the level of disturbances that can negatively affect the biodiversity of the kurgans. We found that legal protection did not provide an ultimate solution for mitigating disturbance factors. Legislative measures could somewhat suppress non-permanent harmful practices (non-significant reduction in garbage deposition inside protected areas), but the relatively short-term (some decades) protection period was not enough for the elimination of permanent constructions. Permanent constructions decrease the area which otherwise could be occupied by grassland specialist species. Trampling and soil disturbance connected to their maintenance (columns of power lines, mapping points and geodetic towers) and 
Table 2

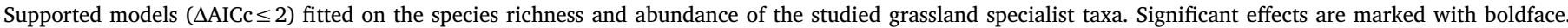
Abbreviations: Imp - importance of a variable within the supported models, NA - factors not included in the supported models.

\begin{tabular}{|c|c|c|c|c|c|c|c|c|c|c|c|}
\hline \multirow[b]{2}{*}{ Dependent variable } & \multicolumn{6}{|l|}{ Outside protected areas } & \multicolumn{5}{|c|}{ Inside protected areas } \\
\hline & Explanatory variables & $\operatorname{Imp}(\%)$ & Estimate & SE & $\mathrm{z}$ value & $p$ & $\operatorname{Imp}(\%)$ & Estimate & SE & $\mathrm{z}$ value & $p$ \\
\hline \multirow[t]{6}{*}{ Plants (SR) } & Woody cover & 100 & -0.003 & 0.002 & 1.916 & 0.055 & 100 & -0.010 & 0.003 & 3.497 & 0.001 \\
\hline & Kurgan height & 100 & 0.080 & 0.016 & 4.951 & $<0.001$ & NA & NA & NA & NA & NA \\
\hline & Disturbance & 88 & -0.271 & 0.078 & 3.437 & 0.001 & 51 & -0.346 & 0.096 & 3.544 & 0.001 \\
\hline & Management & 36 & 0.148 & 0.118 & 1.235 & 0.217 & 100 & 0.286 & 0.106 & 2.650 & 0.008 \\
\hline & Kurgan area & 25 & 0.001 & 0.001 & 1.162 & 0.245 & 100 & 0.001 & 0.001 & 1.580 & 0.114 \\
\hline & Kurgan slope & 24 & 0.009 & 0.008 & 1.142 & 0.254 & 100 & 0.029 & 0.008 & 3.375 & 0.001 \\
\hline \multirow[t]{6}{*}{ Plants (\%) } & Woody cover & 100 & -0.224 & 0.077 & 2.859 & 0.004 & NA & NA & NA & NA & NA \\
\hline & Kurgan height & 100 & 2.416 & 0.850 & 2.795 & 0.005 & 22 & -1.540 & 1.402 & 1.075 & 0.283 \\
\hline & Kurgan area & 100 & -0.004 & 0.002 & 2.361 & 0.018 & NA & NA & NA & NA & NA \\
\hline & Disturbance & 38 & -3.791 & 3.354 & 1.111 & 0.266 & 75 & -8.584 & 4.713 & 1.783 & 0.075 \\
\hline & Management & NA & NA & NA & NA & NA & 1 & 15.681 & 5.523 & 2.779 & 0.005 \\
\hline & Kurgan slope & NA & NA & NA & NA & NA & 16 & -0.368 & 0.470 & 0.765 & 0.444 \\
\hline \multirow[t]{6}{*}{ Ants (SR) } & Kurgan slope & 52 & -0.010 & 0.009 & 1.409 & 0.159 & 7 & 0.007 & 0.011 & 0.671 & 0.502 \\
\hline & Woody cover & 25 & -0.002 & 0.002 & 1.185 & 0.236 & 7 & 0.002 & 0.003 & 0.751 & 0.452 \\
\hline & Kurgan area & 18 & 0.001 & 0.001 & 0.870 & 0.384 & NA & NA & NA & NA & NA \\
\hline & Management & 15 & -0.085 & 0.141 & 0.594 & 0,552 & 73 & -0.204 & 0.127 & 1.574 & 0.115 \\
\hline & Kurgan height & 7 & 0.010 & 0.019 & 0.486 & 0,627 & 51 & 0.056 & 0.030 & 1.787 & 0.074 \\
\hline & Disturbance & NA & NA & NA & NA & NA & 40 & -0.146 & 0.116 & 1.234 & 0.217 \\
\hline \multirow[t]{6}{*}{ Ants (A) } & Woody cover & 100 & -0.010 & 0.004 & 2.218 & 0.027 & NA & NA & NA & NA & NA \\
\hline & Kurgan slope & 100 & -0.119 & 0.021 & 5.568 & $<0.001$ & 17 & 0.029 & 0.038 & 0.761 & 0.446 \\
\hline & Kurgan height & 24 & -0.035 & 0.044 & 0.793 & 0.428 & 22 & 0.121 & 0.116 & 1.018 & 0.308 \\
\hline & Disturbance & 23 & 0.142 & 0.193 & 0.724 & 0.469 & 43 & -0.540 & 0.388 & 1.362 & 0.173 \\
\hline & Kurgan area & NA & NA & NA & NA & NA & 16 & 0.001 & 0.001 & 0.762 & 0.446 \\
\hline & Management & NA & NA & NA & NA & NA & 9 & -0.312 & 0.455 & 0.670 & 0.503 \\
\hline \multirow[t]{6}{*}{ Orthopterans (SR) } & Kurgan slope & 30 & -0.019 & 0.015 & 1.278 & 0.229 & 87 & -0.034 & 0.019 & 1.776 & 0.076 \\
\hline & Kurgan height & 24 & 0.029 & 0.029 & 0.990 & 0.243 & 67 & 0.108 & 0.051 & 2.057 & 0.040 \\
\hline & Disturbance & 13 & 0.106 & 0.118 & 0.886 & 0.126 & 43 & -0.231 & 0.179 & 1.261 & 0.207 \\
\hline & Woody cover & 11 & -0.002 & 0.003 & 0.724 & 0.112 & 18 & -0.005 & 0.005 & 1.155 & 0.248 \\
\hline & Kurgan area & 10 & 0.001 & 0.001 & 0.609 & 0.103 & NA & NA & NA & NA & NA \\
\hline & Management & NA & NA & NA & NA & NA & 56 & 0.307 & 0.185 & 1.627 & 0.104 \\
\hline \multirow[t]{6}{*}{ Orthopterans (A) } & Kurgan height & 53 & 0.096 & 0.060 & 1.575 & 0.527 & 34 & 0.172 & 0.122 & 1.380 & 0.167 \\
\hline & Kurgan slope & 19 & -0.036 & 0.030 & 1.179 & 0.188 & 85 & -0.079 & 0.040 & 1.943 & 0.052 \\
\hline & Kurgan area & 18 & 0.001 & 0.001 & 1.203 & 0.181 & 15 & 0.001 & 0.001 & 1.257 & 0.209 \\
\hline & Management & 14 & -0.379 & 0.427 & 0.874 & 0.138 & 20 & 0.518 & 0.465 & 1.092 & 0.275 \\
\hline & Woody cover & 12 & -0.005 & 0.006 & 0.844 & 0.123 & 21 & -0.009 & 0.010 & 0.977 & 0.329 \\
\hline & Disturbance & NA & NA & NA & NA & NA & 75 & -0.703 & 0.388 & 1.774 & 0.076 \\
\hline \multirow[t]{6}{*}{ True bugs (SR) } & Woody cover & 100 & -0.010 & 0.003 & 4.127 & 0.001 & NA & NA & NA & NA & NA \\
\hline & Management & 100 & -0.603 & 0.186 & 3.197 & 0.001 & 21 & 0.054 & 0.081 & 0.654 & 0.513 \\
\hline & Disturbance & 86 & -0.216 & 0.108 & 1.958 & 0.050 & 100 & -0.229 & 0.074 & 3.010 & 0.003 \\
\hline & Kurgan area & 42 & 0.001 & 0.001 & 1.452 & 0.146 & 50 & 0.001 & 0.001 & 1.455 & 0.146 \\
\hline & Kurgan height & 15 & -0.028 & 0.025 & 1.087 & 0.277 & NA & NA & NA & NA & NA \\
\hline & Kurgan slope & 12 & -0.006 & 0.010 & 0.557 & 0.578 & 30 & -0.007 & 0.007 & 1.043 & 0.297 \\
\hline \multirow[t]{5}{*}{ True bugs (A) } & Woody cover & 100 & -0.015 & 0.005 & 2.938 & 0.003 & NA & NA & NA & NA & NA \\
\hline & Management & 64 & -0.569 & 0.345 & 1.624 & 0.104 & 9 & 0.050 & 0.078 & 0.634 & 0.526 \\
\hline & Kurgan slope & 19 & -0.017 & 0.025 & 0.675 & 0.500 & 19 & 0.019 & 0.026 & 0.713 & 0.476 \\
\hline & Disturbance & NA & NA & NA & NA & NA & 48 & -0.406 & 0.263 & 1.512 & 0.131 \\
\hline & Kurgan area & NA & NA & NA & NA & NA & 28 & 0.001 & 0.001 & 1.117 & 0.264 \\
\hline \multirow[t]{6}{*}{ Rove beetles (SR) } & Woody cover & 100 & -0.019 & 0.013 & 1.490 & 1.490 & 51 & 0.014 & 0.008 & 1.615 & 0.106 \\
\hline & Kurgan slope & 64 & -0.143 & 0.056 & 2.527 & 0.012 & 11 & -0.027 & 0.044 & 0.613 & 0.540 \\
\hline & Disturbance & 37 & 0.434 & 0.358 & 1.193 & 0.233 & 10 & -0.239 & 0.462 & 0.506 & 0.613 \\
\hline & Kurgan height & 31 & 0.121 & 0.089 & 1.334 & 0.182 & NA & NA & NA & NA & NA \\
\hline & Kurgan area & 9 & 0.001 & 0.001 & 0.955 & 0.339 & 17 & 0.001 & 0.001 & 0.766 & 0.444 \\
\hline & Management & NA & NA & NA & NA & NA & 18 & -0.480 & 0.526 & 0.893 & 0.372 \\
\hline \multirow[t]{4}{*}{ Rove beetles (A) } & Kurgan slope & 72 & -0.015 & 0.009 & 1.701 & 0.089 & 26 & -0.009 & 0.008 & 1.073 & 0.283 \\
\hline & Kurgan height & 16 & 0.011 & 0.018 & 0.592 & 0.554 & 21 & -0.022 & 0.025 & 0.844 & 0.399 \\
\hline & Management & 15 & -0.064 & 0.130 & 0.487 & 0.626 & 9 & -0.082 & 0.101 & 0.793 & 0.428 \\
\hline & Woody cover & NA & NA & NA & NA & NA & 49 & 0.003 & 0.002 & 1.557 & 0.119 \\
\hline
\end{tabular}

everyday use (roads, fences, farm houses, cabins, cellars, stables, benches, concrete stairways, shooting ranges, bunkers and hunting towers) might also be sources of additional disturbances. Disturbances associated with the presence of permanent buildings together with the lack of proper management might have supported the establishment of woody species, and also the proportion of problem-species on kurgans located outside the protected areas. Encroachment of unwanted species is highly supported by the presence of roads on the kurgans, as vehicles are effective vectors of human-mediated seed dispersal (Pickering and Mount, 2010).

Woody encroachment on kurgans has the potential to alter the environmental conditions by decreasing light availability, moderating temperature extremes, and increasing nutrient input (Deák et al., 2016b). Furthermore, the increasing amount of litter decreases the 
Table 3

Comparison of the species composition of grassland specialist plant and animal taxa on kurgans outside and inside the protected areas (PERMANOVA; 9999 permutations).

\begin{tabular}{llll}
\hline Group of specialist species & Sum of Squares & $\mathrm{F}$ & $\mathrm{p}$ \\
\hline Grassland specialist plants & 51.51 & 6.645 & 0.001 \\
Grassland specialist ants & 36.73 & 2.661 & 0.016 \\
Grassland specialist orthopterans & 31.97 & 2.539 & 0.003 \\
Grassland specialist true bugs & 57.46 & 1.081 & n.s. \\
Grassland specialist rove beetles & 25.28 & 1.436 & n.s. \\
\hline
\end{tabular}

availability of establishment gaps and alters the soil properties in wooded areas (Deák et al., 2016b; Gazol et al., 2012). Each of these factors can support weedy species, reduce the germination and establishment success of grassland species, and lead to considerable changes in the biotic interactions (e.g. competition for light and resources) (Sudnik-Wójcikowska and Moysiyenko, 2014). Despite many grassland specialist plant species, especially the long-lived clonal ones, can cope with the effects of woody encroachment, they are likely outcompeted from the vegetation in the long run (Deák et al., 2018; Honnay and Bossuyt, 2005). In our study, negative changes in the species composition were well reflected by the naturalness scores calculated for the total vegetation and for the herbaceous vegetation. Naturalness was significantly lower on kurgans outside the protected areas due to the increased proportion of weedy and generalist species. Although the abundance and species richness of grassland specialists were not affected by the presence or absence of protection, our results suggest that these unfavourable changes in the species composition pose a serious future threat for grassland biodiversity on kurgans outside the protected areas.

\subsection{Grassland specialist taxa}

We found that kurgans could effectively support grassland biodiversity even outside the protected areas, since the species richness and abundance of the studied grassland specialist taxa were the same on kurgans outside and inside the protected areas. Given the considerable differences in the life strategies and dispersal ability of the studied taxa, this uniform pattern might be an outcome of different processes.

\subsubsection{Plants}

For plants, even small-sized and completely isolated kurgans can act as refuges. Traits related to persistence such as sessile life form, limited seed dispersal ability and ability for clonal reproduction can support the long-term existence of grassland specialist plants even on isolated kurgans (Deák et al., 2018; Dembicz et al., 2018; Lindborg et al., 2014; Novák and Konvička, 2006). However, clonal species with low dispersal ability are highly vulnerable to stochastic large-scale disturbances given their low potential for regeneration and immigration (Honnay and Bossuyt, 2005). The pattern that the species richness of grassland specialist species was the same on kurgans outside and inside the protected areas implies that plants confined to dry grasslands can survive for a certain period even under anthropogenically altered habitats and landscape structure (Brückmann et al., 2010; Helm et al., 2006; Rösch et al., 2015).

Based on the results of the model selection we can assume that grassland specialist plants inhabiting the kurgans are more sensitive for the local habitat conditions than the grassland specialist arthropods. Outside the protected areas grassland specialist plants favoured high, undisturbed kurgans with a low cover of woody species. Inside the protected areas grassland specialist plants preferred managed kurgans with steep slopes, low level of disturbance, and low cover of woody species. Whilst disturbance and woody encroachment can negatively affect the habitat conditions for the grassland specialist plants as discussed in the 'Disturbance factors' section, the negative effects can be counterbalanced by the shape of the kurgans. Besides providing a physical barrier against ploughing, the hill shape of the kurgans supports the maintenance of a high habitat heterogeneity even within a small area (Lisetskii et al., 2016; Sudnik-Wójcikowska and Moysienko, 2014). Thus, the small size of the kurgans is probably counterbalanced by the topographical heterogeneity, which provides a wide array of micro-habitats (top, slopes with different inclination and bottom of the kurgan) characterised by various environmental conditions (e.g. microclimate, level of solar radiation, soil properties), which support the establishment and co-existence of a wide set of grassland specialist species (Báldi, 2008; Deák et al., 2016b; Lisetskii et al., 2016). Furthermore, due to their relief, kurgans are considerably drier habitats than their environments, which supports the existence of grassland specialist plants confined to xeric habitats and hinders the invasion of problem-species preferring milder habitat conditions (Deák et al., 2016b; Lisetskii et al., 2016). In the protected areas grassland specialist plants benefitted from the active management, which was predominantly grazing. The most probably the open microsites created by biomass removal and trampling together with the increased propagule availability by zoochory increased both the species richness and abundance of grassland specialist plant species.

\subsubsection{Ants}

The approximately 0.2 ha area of a kurgan is large enough for the long-term maintenance of ant colonies, as most grassland specialist ants have a low activity radius and hold a small territory. The average nest densities of the two most abundant grassland specialist ant species (Lasius bombycina and Tetramorium caespitum) are 25-50 and 20-90 nests $/ 100 \mathrm{~m}^{2}$ in Central-Europe (Seifert, 2018). This probably allows the co-existence of several colonies even in completely isolated kurgans. We found no differences in the abundance and species richness of grassland specialist ants on kurgans outside and inside the protected areas. The possible reason is that contrary to the generally low dispersal ability of grassland specialist plants $(<100 \mathrm{~m}$; Novák and Konvička, 2006), ants have a high dispersal potential by alate (winged) queens which can disperse over several kilometres of hostile habitats that otherwise would act as barriers for the less mobile walking individuals (Mabelis, 1994). The high mobility of queens supports the maintenance of a functioning meta-population network even in fragmented landscapes; thus, maintains a high genetic diversity, increases the viability of the populations and lowers the chance of local extinctions (Brückmann et al., 2010; Mabelis, 1994; Tscharntke et al., 2012).

Since the majority of ants, especially the grassland specialist species are strongly thermophilic, temperature is one of the main factors affecting their abundance, richness and assemblage composition (Hölldobler and Wilson, 1990). The influence of the vegetation composition and structure on ant assemblages is also well known and has been reported by several authors (Lassau and Hochuli, 2004). Vegetation cover, for instance, not only determines specific microclimatic conditions (increased soil moisture, reduced temperature) that may influence ants through foraging activity and suitability of nesting sites, but also the abundance, availability and quality of food resources that they can utilise (Andersen, 1986). Increased woody cover creates humid and shady microhabitats, which are likely much less attractive to ants inhabiting open habitats, leading to the decrease of abundance of these species. Increased xeric conditions due to the steeper slopes of kurgans, however, may be unfavourable even for grassland specialist ants, preventing them from increasing their abundance in these habitats.

\subsubsection{Orthopterans}

Various abiotic conditions due to the high micro-habitat heterogeneity of the kurgans (Lisetskii et al., 2016) likely provided proper conditions for the populations of orthopteran species typical to xeric (e.g. Platycleis affinis, Euchorthippus declivus), mesic (e.g. Chorthippus parallelus, Chorthippus oschei) and even moist (Polysarcus denticauda, 
Metrioptera roeselii) grasslands. The results of the model selection supported this assumption, as in protected areas higher kurgans, which probably hold contrasting micro-habitats, harboured more grassland specialist orthopteran species than small ones. Since locusts (Acridoidea) which compose a considerable part of orthopterans are polyphagous, their presence is mostly determined by the structure typical to grasslands, and not necessarily by the species composition of the vegetation. Due to their moderate mobility and low dietary specialisation small (50-200 individuals) populations of flightless apterous and brachypterous (micropterous) orthopteran species can exist even in a grassland patch harboured by an isolated kurgan, and they can use these habitat patches as refuge (Köhler, 1996; Krausz et al., 2000). Holopterous (macropterous) forms of locusts with a high mobility can also use the neighbouring arable lands, especially grassland-like habitats of grain, alfalfa, soy and pea fields as temporary habitats. Like winged queen ants, holopterous orthopteran species can also maintain the meta-population connections even in transformed landscapes, using kurgans as core population areas and the neighbouring arable lands as temporal habitats (Marini et al., 2010; Torma et al., 2018).

\subsubsection{True bugs and rove beetles}

The good mobility and low level of food specialisation of the collected grassland specialist true bugs and rove beetles might be responsible for the lack of differences in their species numbers and abundance outside and inside the protected landscapes. Being mobile species true bugs and rove beetles can use SNFs as stepping stones and as temporal habitats in transformed non-protected landscapes (Tóthmérész et al., 2014). As many true bug and rove beetle species typical to grassland habitats can also utilise arable lands for feeding, transformed landscapes are more permeable for them than for plants and ants (Balog et al., 2008). However, contrary to arable lands, SNFs with permanent grassland vegetation are essential overwintering places for several true bug and rove beetle species that require herbaceous vegetation for laying their eggs (Balog et al., 2008). Kurgans can also act as temporal refuges for these arthropods; after harvesting the green biomass from the arable lands, grasslands on kurgans may serve as important habitats providing essential resources such as food, shelter and oviposition surface for true bugs and rove beetles. This likely results in a transient concentration of these species on kurgans following the harvest, from where they can disperse the following year and repopulate the neighbouring areas by their spillover (Tscharntke et al., 2012).

Disturbance and the high cover of woody vegetation suppressed the populations of grassland specialist true bugs by similar mechanisms that were proposed in case of plants (Torma and Gallé, 2011). The fact that management had a negative effect on true bug diversity only outside the protected areas suggests that management should be improved in those sites. Extensive grazing, which was typical in the protected areas, is more advantageous for grassland specialist true bugs in long run than mowing which was typical outside the protected areas (Torma et al., 2019). As the date and frequency of the mowing outside the protected areas are not fitted to the conservation aims, presumably the improper cutting regime (too frequent, wrong timing) might decrease the diversity of true bugs (e.g. Morris, 1979). Like in the case of ants, species richness of grassland specialist rove beetles decreased on kurgans with steep slopes presumably because of the xeric habitat conditions.

\subsection{Species composition}

Even there were no differences in the species richness and abundance of grassland specialist taxa outside and inside the protected areas, we found significant differences in the species composition of less mobile species groups (e.g. plants, ants and orthopterans). Less mobile species are generally highly affected by landscape transformation, especially by the isolation and the altered management regimes
(Tscharntke et al., 2012). We assume that the species pool of kurgans outside the protected areas might preserve a set of the historical species pool that can cope with the altered habitat and landscape conditions. Differences in the species composition of kurgans outside and inside the protected areas might also be originated from the differences in the original historical species pools. Landscape transformations generally affected sites with habitat conditions preferable for agricultural use; thus, these habitats likely differed from the ones preserved in the protected areas (Bhagwat and Rutte, 2006). Mobile species such as true bugs and rove beetles can disperse over extensive patches of unsuitable habitats and re-establish after a stochastic extinction event. Thus, these species seemed less sensitive to landscape-level changes, since even transformed landscapes with a moderate level of grassland patches are permeable for them (Rösch et al., 2015).

\subsection{Connection between conservation values and ecosystem services}

Besides that kurgans provide spiritual and landscape values for the society, they are sources of several indirect use values supporting agricultural production. Indirect use values are mostly related to the grassland habitats of the kurgans, which harbour several beneficial species having important roles in pollination, improving soil properties and biological pest control; all of these support crop production in agroecosystems (Batáry et al., 2015; Tscharntke et al., 2012). The high species number (335) of entomophilous herbaceous plants found on the surveyed kurgans can continuously provide nectar for pollinator populations and thus support their long-term existence even in transformed landscapes. The dense network of channels, chambers and galleries of ants inhabiting kurgans increases the porosity of the soil, improves soil aeration and water infiltration, and reduces bulk density (Folgarait, 1998). Furthermore, ants stimulate the abundance of ammonifying bacteria which can locally increase the concentrations of nutrients. These positive effects can spill over to the neighbouring croplands and improve crop production (Folgarait, 1998).

Several true bug species of the Nabis, Orius and Dicyphus genera were found on the kurgans outside the protected areas. These species are effective biological control agents of agricultural pests; thus they can increase crop production and decrease the amount of pesticides needed in agricultural landscapes (Perdikis et al., 2011). Rove beetles, as active polyphagous predators confined to the studied SNFs have also an important role in biological plant protection. Species of the Tachyporus, Stenus, Ocypus genera are important predators of pests, and some species of the genus Aleochara are known to be the parasitoids of fly pupae (Balog et al., 2008). Many rove beetle species have specialised in using decaying organic material or fungi as food resources; thus they contribute to the decomposition, and to the dispersal of fungal spores and hyphae in agricultural landscapes (Tscharntke et al., 2005).

\section{Conservation remarks}

As shown by our study, kurgans as SNFs can act as an additional pillar of biodiversity conservation. They extend the borders of the protected areas by maintaining populations of grassland specialist plants and arthropods even in transformed landscapes. However, our results highlight that for long-term conservation of the kurgans a novel integrated approach would be necessary. The basic conservation actions for kurgans should involve the elimination of woody vegetation and the reduction of disturbances associated with the presence of roads, buildings and garbage deposition. Maintenance of grassland habitats on the kurgans requires proper management, which might be different from the generally applied measures in the neighbouring grasslands. As was shown by the study of Deák et al. (2017) on Central-Asian kurgans, given their steep slopes and the dry habitat conditions, grasslands located on kurgans are more sensitive for the erosion and biomass removal caused by overgrazing than the flat neighbouring grasslands.

The small size of the kurgans makes their management challenging, 
but at the same time it provides opportunity for establishing a close connection between conservation and the local human populations (Hunter et al., 2017). Based on the findings of Valkó et al. (2018b) kurgans are proper objects for targeted grassland management actions and for small-scale plant reintroduction projects by which their biodiversity can be significantly increased. These actions focus on a small area and many of them are of low budget, therefore they are ideal tasks for local cooperatives such as NGOs (Valkó et al., 2018b). A more horizontal solution would be the development of the already existing regulations in the CAP about kurgan protection. The integration of kurgan protection into the CAP has highly supported the maintenance of grasslands on kurgans by prohibiting ploughing and afforestation, but it does not support the elimination of other threats such as the presence of buildings or roads and does not provide financial sources for the restoration of grassland habitats and ecosystem functions connected to the kurgans. We think that such improvements in the supporting system would be important steps forward, as in this way farmers would become interested in a more active kurgan protection and restoration.

Knowledge transfer between conservationists, landscape planners and farmers would also be essential to recognise the synergies and trade-offs in the simultaneous maintenance of conservational and economic interests (Plieninger et al., 2015). It is especially important as due to the spatial spillover of the ecosystem services provided by the well-functioning SNFs, there is a spatial mismatch between the costs incurred regarding the management of an SNF (individual owner, parcel-level) and those who receive the benefits (neighbouring owners, local population, landscape-level) (Bauer et al., 2017). Recognition of the spatial and functional complexity of the services provided by the kurgans can contribute to several levels of social processes. It can drive landowner's decision making by harmonising crop production with conservation, motivate local population for preserving and getting familiar with their historical heritage, and can inform landscape planners about the possibilities for optimising the gathered values and potentials for landscape-scale restoration projects (Plieninger et al., 2015). This integrative approach might considerably support the preservation of the grassland habitats harboured the kurgans.

\section{Declaration of Competing Interest}

The authors declare no competing interests.

\section{Acknowledgements}

The authors were supported by the NKFI KH 130338 project (BD) and the NKFI FK 124404 (OV), NKFI KH 126476 (OV), NKFI KH 126477 (BT), OTKA K 116639 (BT), NRDI Office (NKFIH) PD 121126 (ÁB), NKFI K119225 (PT),NKFI KH 129483 (PT). BD was supported by the National Science Fund (contract KП-06-H21/2). The project was supported by the Bolyai János Research Scholarship of the Hungarian Academy of Sciences (BD, OV). BD was supported by the ÚNKP-18-4DE-9 New National Excellence Programme of the Ministry of Human Capacities.

\section{Appendix A. Supplementary data}

Supplementary material related to this article can be found, in the online version, at doi:https://doi.org/10.1016/j.biocon.2019.108254.

\section{References}

Andersen, A.N., 1986. Diversity, seasonality and community organization of ants at ad jacent sites in South-Eastern Australia. Aust. J. Ecol. 34, 53-64.

Báldi, A., 2008. Habitat heterogeneity overrides the species-area relationship. J. Biogeogr. 35, 675-681.

Balog, A., Marko, V., Adam, L., 2008. Rove beetles (Coleoptera: Staphylinidae) collected during the long term ecological research in a Hungarian oak forest. J. Environ. Biol.
29, 263-266

Barton, K., 2011. MuMIn: Multi-Model Inference. R Package Version 1.0. R Foundation for Statistical Computing, Vienna, Austria.

Batáry, P., Dicks, L.V., Kleijn, D., Sutherland, W.J., 2015. The role of agri-Environment Schemes in conservation and Environmental management: European AgriEnvironment Schemes. Conserv. Biol. 29, 1006-1016.

Bauer, D.M., Bell, K.P., Nelson, E.J., Calhoun, A.J.K., 2017. Managing small natural features: a synthesis of emergent socio-economic issues and opportunities. Biol. Conserv. 211, 80-87.

Bhagwat, S.A., Rutte, C., 2006. Sacred groves: potential for biodiversity management. Front. Ecol. Env. 4, 519-524.

Biró, M., Bölöni, J., Molnár, Zs., 2018. Use of long-term data to evaluate loss and endangerment status of Natura 2000 habitats and effects of protected areas. Conserv. Biol. 3, 660-671.

Borhidi, A., 1995. Social behaviour types, the naturalness and relative ecological in dicator values of the higher plants in the Hungarian Flora. Acta Bot. Hung. 39, 97-181.

Brückmann, S., Krauss, J., Steffan-Dewenter, I., 2010. Butterfly and plant specialists suffer from reduced connectivity in fragmented landscapes. J. Appl. Ecol. 47, 799-809.

Burnham, K., Anderson, D., 2002. Model Selection and Multimodel Inference: A Practical Information-Theoretic Approach. Springer-Verlag, New York.

Colding, J., Folke, C., 2001. Social taboos: 'invisible' systems of local resource management and biological conservation. Ecol. Appl. 11, 584-600.

Deák, B., Tölgyesi, C., Kelemen, A., Bátori, Z., Gallé, R., Bragina, T.M., Abil, Y.A., Valkó, O., 2017. Vegetation of steppic cultural heritage sites in Kazakhstan - effects of micro-habitats and grazing intensity. Plant Ecol. Divers. 10, 509-520.

Deák, B., Tóthmérész, B., Valkó, O., Sudnik-Wójcikowska, B., Bragina, T.M., Moysiyenko, I.I., Apostolova, I., Bykov, N., Dembicz, I., Török, P., 2016a. Cultural monuments and nature conservation: the role of kurgans in maintaining steppe vegetation. Biodivers. Conserv. 25, 2473-2490.

Deák, B., Valkó, O., Török, P., Kelemen, A., Bede, Á., Csathó, A.I., Tóthmérész, B., 2018. Landscape and habitat and filters jointly drive richness and abundance of grassland specialist plants in terrestrial habitat islands. Landsc. Ecol. 33, 1117-1132.

Deák, B., Valkó, O., Török, P., Tóthmérész, B., 2016b. Factors threatening grassland specialist plants - a multi-proxy study on the vegetation of isolated grasslands. Biol. Conserv. 204, 255-262.

Dembicz, I., Moysiyenko, I.I., Shaposhnikova, A., Vynokurov, D., Kozub, L., SudnikWójcikowska, B., 2016. Isolation and patch size drive specialist plant species density within steppe islands: a case study of kurgans in southern Ukraine. Biodivers. Conserv. 25, 2289-2307.

Dembicz, I., Szczeparska, L., Moysiyenko, I.I., Wódkiewicz, M., 2018. High genetic diversity in fragmented Iris pumila L. populations in Ukrainian steppe enclaves. Basic Appl. Ecol. 28, 37-47.

Dudley, N., Higgins-Zogib, L., Mansourian, S., 2009. The links between protected areas, faiths, and sacred natural sites. Conserv. Biol. 23, 568-577.

Council Directive 92/43/EEC of 21 May 1992 on the conservation of natural habitats and of wild fauna and flora.

European Environmental Agency, 2019. Natura 2000 Network Viewer. http:// natura2000.eea.europa.eu/.

Faraway, J.J., 2014. Linear Models with R. Chapman \& Hall, London.

Fick, S.E., Hijmans, R.J., 2017. Worldclim 2: new 1-km spatial resolution climate surfaces for global land areas. Int. J. Climatology 37, 4302-4315.

Fitzsimons, J.A., Michael, D.R., 2017. Rocky outcrops: a hard road in the conservation of critical habitats. Biol. Conserv. 211, 36-44.

Fletcher, R.J., Didham, R.K., Banks-Leite, C., Barlow, J., Ewers, R.M., Rosindell, J., Holt, R.D., Gonzalez, A., Pardini, R., Damschen, E.I., Melo, F.P.L., Ries, L., Prevedello, J.A., Tscharntke, T., Laurance, W.F., Lovejoy, T., Haddad, N.M., 2018. Is habitat fragmentation good for biodiversity? Biol. Conserv. 226, 9-15.

Folgarait, P.J., 1998. Ant biodiversity and its relationship to ecosystem functioning: a review. Biodivers. Conserv. 7, 1221-1244.

Frascaroli, F., Bhagwat, S., Guarino, R., Chiarucci, A., Schmid, B., 2016. Shrines in Central Italy conserve plant diversity and large trees. Ambio 45, 468-479.

Gazol, A., Tamme, R., Takkis, K., Kasari, L., Saar, L., Helm, A., Pärtel, M., 2012. Landscape and small-scale determinants of grassland species diversity: direct and indirect influences. Ecography 35, 944-951.

Grime, J.P., 1979. Plant Strategies and Vegetational Processes. Wiley and Sons, New York.

Hammer, $\varnothing$., Harper, D.A.T., Ryan, P.D., 2001. PAST: paleontological statistics software package for education and data analysis. Paleontol. Electron. 4, 1-9.

Heinken, T., Weber, E., 2013. Consequences of habitat fragmentation for plant species: do we know enough? Perspect. Plant. Ecol. Evol. Sys. 15, 205-216.

Helm, A., Hanski, I., Pärtel, M., 2006. Slow response of plant species richness to habitat loss and fragmentation. Ecol. Lett. 9, 72-77.

Honnay, O., Bossuyt, B., 2005. Prolonged clonal growth: escape route or route to extinction? Oikos 108, 427-432.

Hölldobler, B., Wilson, E.O., 1990. The Ants. Harvard University Press, Cambridge.

Hunter, M.L., Acuña, V., Bauer, D.M., Bell, K.P., Calhoun, A.J.K., Felipe-Lucia, M.R., Fitzsimons, J.A., González, E., Kinnison, M., Lindenmayer, D., Lundquist, C.L., Medellin, R.A., Nelson, E.J., Poschlod, P., 2017. Conserving small natural features with large ecological roles: a synthetic overview. Biol. Conserv. 211, 88-95.

IBM Corp. Released, 2013. IBM SPSS Statistics for Windows, Version 22.0. IBM Corp., Armonk, NY.

Jakobsson, S., Bernes, C., Bullock, J.M., Verheyen, K., Lindborg, R., 2018. How does roadside vegetation management affect the diversity of vascular plants and invertebrates? A systematic review. Environ. Evid. 7, 17.

Köhler, G., 1996. The ecological background of population vulnerability in Central European grasshoppers and bushcrickets: a brief review. In: Settle, J., Margules, C., 
Poschold, P., Henle, K. (Eds.), Species survival in Fragmented Landscapes. Kluwer Academic, Dordrecht, pp. 290-298.

Kowarik, I., Buchholz, S., von der Lippe, M., Seitz, B., 2016. Biodiversity functions of urban cemeteries: evidence from one of the largest Jewish cemeteries in Europe. Urban For. Urban Green. 19, 68-78.

Krausz, K., Pápai, J., Körmöczi, L., Horváth, A., 2000. Structure of Orthoptera assemblages in step-like habitat islands and neighbouring grasslands. Articulata 15, $167-177$.

Lassau, S.A., Hochuli, D.F., 2004. Effects of habitat complexity on ant assemblages. Ecography 27, 157-164.

Lindborg, R., Plue, J., Andersson, K., Cousins, S.A.O., 2014. Function of small habitat elements for enhancing plant diversity in different agricultural landscapes. Biol. Conserv. 169, 206-213.

Lisetskii, F.N., Sudnik-Wójcikowska, B., Moysiyenko, I.I., 2016. Flora differentiation among local ecotypes in the transzonal study of forest-steppe and steppe mounds. Biol. Bull. 43, 169-176.

Löki, V., Molnár V, A., Süveges, K., Heimeier, H., Takács, A., Nagy, T., Fekete, R., LovasKiss, Á., Kreutz, C.A.J.K., Sramkó, G., Tökölyi, J., 2019. Predictors of conservation value of Turkish cemeteries: a case study using orchids. Landsc. Urban Plan. 186, $36-44$.

Mabelis, A.A., 1994. Flying as a survival strategy for wood ants in a fragmented landscape. Mem. Zool. 48, 147-170.

Marini, L., Bommarco, R., Fontana, P., Battisti, A., 2010. Disentangling effects of habitat diversity and area on orthopteran species with contrasting mobility. Biol. Conserv. 143, 2164-2171.

Molnár V, A., Nagy, T., Löki, V., Süveges, K., Takács, A., Bódis, J., Tökölyi, J., 2017. Graveyards as refuges for Turkish orchids against salep harvesting. Ecol. Evol. 23, $11257-11264$.

Morris, M.G., 1979. Responses of grassland invertebrates to management by cutting. II Heteroptera. J. Appl. Ecol. 16, 417-432.

Novák, J., Konvička, M., 2006. Proximity of valuable habitats affects succession patterns in abandoned quarries. Ecol. Eng. 26, 113-122.

Pakeman, R., Hewison, R.L., Lewis, R.J., 2016. Drivers of species richness and compositional change in Scottish coastal vegetation. Appl. Veg. Sci. 20 (2), 183-193.

Perdikis, D., Fantinou, A., Lykouressis, D., 2011. Enhancing pest control in annual crops by conservation of predatory Heteroptera. Biol. Control 59, 13-21.

Pickering, C.M., Mount, A., 2010. Do tourists disperse weed seeds? A global review of unintentional human-mediated terrestrial seeds dispersal on clothing, vehicles and horses. J. Sustain. Tour. 18, 239-256.

Plieninger, T., Bieling, C., Fagerholm, N., Byg, A., Hartel, T., Hurley, P., López-Santiago, C.A., Nagabhatla, N., Oteros-Rozas, E., Raymond, C., van der Horst, D., Huntsinger, L., 2015. The role of cultural ecosystem services in landscape management and planning. Curr. Opin. Environ. Sust. 14, 28-33.

Poschlod, P., Kiefer, S., Trankle, U., Fischer, S., Bonn, S., 1998. Plant species richness in calcareous grasslands as affected by dispersability in space and time. Appl. Veg. Sci. 1, 75-90.

Poschlod, P., Braun-Reichert, R., 2017. Small natural features with large ecological roles in ancient agricultural landscapes of Central Europe - history, value, status, and conservation. Biol. Conserv. 211, 60-68.

R Core Team, 2019. R: A Language and Environment for Statistical Computing. R Foundation for Statistical Computing, Vienna.

Rösch, V., Tscharntke, T., Scherber, C., Batáry, P., 2015. Biodiversity conservation acros taxa and landscapes requires many small as well as single large habitat fragments. Oecologia 179, 209-222.

Rutte, C., 2011. The sacred commons: conflicts and solutions of resource management in sacred natural sites. Biol. Conserv. 144, 2387-2394.

Seifert, B., 2018. The Ants of Central and North Europe. Lutra Verlag- und Vertriebsgesellschaft, Tauer.

Sudnik-Wójcikowska, B., Moysiyenko, I.I., 2014. Indicative role of the flora of kurgans in the 'Wild Field' (southern Ukraine). Monit. Srodowiska Przyrodniczego. 15, 75-83.

Tälle, M., Deák, B., Poschlod, P., Valkó, O., Vesterberg, L., Milberg, P., 2016. Grazing vs. mowing: a meta-analysis of biodiversity benefits for grassland management. Agric. Ecosyst. Environ. 15, 200-212.

Torma, A., Gallé, R., 2011. Fine scale pattern of true bug assemblages (Heteroptera) across two natural edges. Acta Zoologica Academiae Scientiarum Hungaricae 57, 367-383.

Torma, A., Bozsó, M., Gallé, R., 2018. Secondary habitats are important in biodiversity conservation: a case study on orthopterans along ditch banks. Anim. Biodivers. Conserv. 41, 97-108.

Torma, A., Császár, P., Bozsó, M., Deák, B., Valkó, O., Kiss, O., Gallé, R., 2019. Species and functional diversity of arthropod assemblages (Araneae, Carabidae, Heteroptera and Orthoptera) in grazed and mown salt grasslands. Agric. Ecosys. Environ. 273, 70-79.

Tóth, C.A., Rákóczi, A., Tóth, S., 2018. Protection of the state of prehistoric mounds in Hungary: law as a conservation measure. Conserv. Manage. Arch. Sites 20, 113-142.

Tóthmérész, B., Nagy, D.D., Mizser, S., Bogyó, D., Magura, T., 2014. Edge effects on ground-dwelling beetles (Carabidae and Staphylinidae) in oak forest-forest edge-. grassland habitats in Hungary. Eur. J. Entomol. 111, 686-691.

Tscharntke, T., Klein, A.M., Kruess, A., Steffan-Dewenter, I., Thies, C., 2005. Landscape perspectives on agricultural intensification and biodiversity - ecosystem service management. Ecol. Lett. 8, 857-874.

Tscharntke, T., Tylianakis, J., Rand, T., Didham, R., Fahrig, L., Batáry, P., Bengtsson, J., Clough, Y., Crist, T., Dormann, C., Ewers, R., Fründ, J., Holt, R., Holzschuh, A., Klein, A., Kleijn, D., Kremen, C., Landis, D., Laurance, W., Lindenmayer, D., Scherber, C., Sodhi, N., Steffan-Dewenter, I., Thies, C., van der Putten, W., Westphal, C., 2012. Landscape moderation of biodiversity patterns and processes - eight hypotheses. Biol. Rev. 87, 661-685.

Valkó, O., Tóth, K., Kelemen, A., Miglécz, T., Radócz, S., Sonkoly, J., Tóthmérész, B., Török, P., Deák, B., 2018a. Cultural heritage and biodiversity conservation - plant introduction and practical restoration on ancient burial mounds. Nat. Conserv. 24, 65-80.

Valkó, O., Venn, S., Zmihorski, M., Biurrun, I., Labadessa, R., Loos, J., 2018b. The challenge of abandonment for the sustainable management of Palaearctic natural and semi-natural grasslands. Hacquetia 17, 5-16. 